\title{
SSRI ve sildenafil kombinasyonlarının vaz deferens kasılması üzerine etkileri
}

\author{
The effects of SSRI's plus sildenafil combination on vas deferens contraction \\ Elif Aksöz*a, S. Sırrı Bilge ${ }^{b}$, Fatih İlkaya ${ }^{b}$, B. Duygu Baş ${ }^{b}$, Yüksel Kesim $^{b}$, Süleyman Çelik $^{b}$ \\ a Balıkesir Üniversitesi, Tıp Fakültesi, Farmakoloji Anabilim Dall, Balıkesir \\ ${ }^{b}$ Ondokuz Mayıs Üniversitesi Tip Fakültesi, Farmakoloji Anabilim Dalı, Samsun
}

\begin{tabular}{|c|c|}
\hline \multicolumn{2}{|c|}{ MAKALE BİLGÍLERİ } \\
\hline \multicolumn{2}{|c|}{ Makale Geçmişi: } \\
\hline Geliş & $21 / 05 / 2010$ \\
\hline Kabul & $03 / 06 / 2010$ \\
\hline
\end{tabular}

\section{* Yazışma Adresi: \\ Elif Aksöz \\ Balıkesir Üniversitesi, Tıp Fakültesi, Farmakoloji Anabilim Dalı, Çağış Kampüsü, Balıkesir e-posta: aksoz@balikesir.edu.tr}

\section{SSRI \\ Sildenafil \\ Ejakülasyon \\ Rat \\ Vaz Deferens \\ 5-HTT \\ Key Words : \\ SSRIs \\ Sildenafil \\ Ejaculation \\ Rat \\ Vas Deferens \\ 5-HTT}

Anahtar Kelimeler:

\section{ÖZET}

Serotonin geri alım inhibitörleri (SSRI) yan etki olarak gecikmiş ejakülasyon oluştururlar. $\mathrm{Bu}$ nedenle Prematür Ejakülasyon tedavisinde kullanılmaktadırlar. Son yayınlarda siklik GMP'ye özgü fosfodiesteraz tip 5 enziminin seçici inhibitörü sildenafilin, prematür ejakülasyon tedavisinde yararlı olabileceği bildirilmiştir. Bununla birlikte; bazı çalışmalarda SSRI kullanımına bağlı olarak oluşan gecikmiş ejakülasyonun tedavisinde de kullanılabileceği gösterilmiştir. Biz bu çalışmada, SSRI ve sildenafil kombinasyonlarının uygulamasının vaz deferens kasılması üzerine etkilerini sıçan izole vaz deferensinde araştırdık. Kontrol grubundaki siçanlara 15 gün boyunca $10 \mathrm{ml} / \mathrm{kg}$ serum fizyolojik (SF) intaperitoneal (i.p) olarak uygulandı. SSRI gruplarına 14 gün boyunca fluoksetin $(20 \mathrm{mg} / \mathrm{kg})$, sertralin $(10 \mathrm{mg} / \mathrm{kg})$ ya da sitalopram $(10 \mathrm{mg} / \mathrm{kg})$ i.p. olarak verildi ve 15 . gün $10 \mathrm{ml} / \mathrm{kg}$ SF uyguland1. Kombinasyon gruplarında, 14 gün boyunca SSRI, 15.gün sildenafil $(10 \mathrm{mg} / \mathrm{kg})$ uygulandı. Sildenafil grubuna ise 14 gün boyunca SF, 15. gün sildenafil i.p. olarak uygulandı. Siçanlar zorunlu yüzdürme testine tabi tutuldu. Testi takiben vaz deferensleri çıkarılarak organ banyosuna yerleştirildi ve elektriksel alan stimülasyonu (EAS) uygulanarak kasılma yanıtları kaydedildi. SSRI'lar EAS sonucu oluşan vaz deferens kasılma yanıtlarını baskıladı. Sildenafil, fluoksetin ve sitalopram ile birlikte verildiğinde bu baskılanma azalırken; sertralin ile birlikte verildiğinde azalmadı. Sonuçlar, sildenafilin, serotonerjik taşıyıcı moleküllere bağlanma gücü daha düşük olan fluoksetin ve sitalopramın sinaptik aralıkta 5-HT artırıcı etkilerini sınırlamış, fakat daha güçlü bağlandığı için sertralinin bu etkisini sınırlayamamış olabileceğini düşündürdü. Biz, sildenafil ve SSRI kombinasyonlarının vaz deferens kasılmaları üzerine etkilerinin farklılı̆̆ında 5-HTT'nin rolü olabileceğini düşünüyoruz.

J. Exp. Clin. Med., 2009; 26:173-179

\begin{abstract}
Selective serotonin reuptake inhibitors (SSRIs) induced delayed ejaculation as an adverse effect. Cause of this they have been used to treat Premature Ejaculation. Recent studies have suggested that sildenafil, a selective inhibitor of cyclic GMP specific phosphodiesterase type 5, could be beneficial in the treatment of PE. However, some studies demonstrated that sildenafil is helpfull in the treatment of SSRI induced delayed ejaculation. In the present study, we examined the effects of administration of the SSRIs plus sildenafil combination on vas deferens contractions on isolated rat vas deferens. Saline $(10 \mathrm{ml} / \mathrm{kg})$ was administered to the control group rats for 15 days intraperitoneally (i.p). Fluoxetine $(20 \mathrm{mg} / \mathrm{kg})$, sertraline $(10 \mathrm{mg} / \mathrm{kg})$ or citalopram $(10 \mathrm{mg} / \mathrm{kg})$ were administered to the SSRI groups for 14 days i.p and $10 \mathrm{ml} / \mathrm{kg}$ saline was administered at 15 th day. SSRIs were administered to the combination groups for 14 days i.p. and $10 \mathrm{ml} / \mathrm{kg}$ sildenafil was administered at 15 th day. Saline $(10 \mathrm{ml} / \mathrm{kg})$ was administered to the sildenafil group for 14 days i.p and at 15 th day, $10 \mathrm{mg} / \mathrm{kg}$ sildenafil was administered. Rats were exposed to the forced swimming test. After the test rats vas deferens were removed and placed in organ baths and the contraction responses induced by electrical field stimulation (EFS) were recorded. The contraction responses induced by EFS were inhibited by SSRIs. This inhibition effect was antagonized by sildenafil when administered with fluoxetine or citalopram but not with sertraline. The results thought that sildenafil could have limited the 5-HT increasing effects of fluoksetin and citalopram, having lower potency for binding to the 5-HTT in synaptic cleft, whereas could not have limited this effect of sertraline, having more potency for binding to the
\end{abstract}


5-HTT. We suggest that 5-HTT may have a role on differantiated effects of SSRIs plus sildenafil combination on vas deferens contractions.

(C) 2009 OMÜ Tüm Hakları Saklıdır.

\section{Giriş}

İlk seçici serotonin geri alım inhibitörü (SSRI) fluoksetinin antidepresan olarak kullanılmaya başlanmasından bu yana SSRI'lar, depresyon tedavisinde en çok kullanılan ilaçlardır. Trisiklik antidepresanlar ve Monoamin oksidaz inhibitörlerine (MAOI) göre daha az yan etkiye sahip olmakla birlikte, SSRI kullanan hastalar arasında \%40-70 oranında seksüel işlev bozuklukları bildirilmiştir (Nurnberg, 2008). Bu yan etkiler arasında en sık bildirilenlerden biri de ejakülasyondaki gecikmedir. İntravajinal ejakülasyon latensinin artması ile karakterize olan gecikmiş ejakülasyonun, SSRI tedavisi alan hastaların en az dörtte birinde gözlendiği bildirilmektedir (Seidman, 2006). SSRI'lar bu yan etkilerinden dolayı prematür ejakülasyon (PE) tedavisinde de kullanılmaktadırlar (Waldinger ve Olivier, 2004).

Ejakülasyon, emisyon ve ekspulsiyon olmak üzere iki faza ayrilır (Giuliano ve Clement, 2005). Emisyon fazında, seminal veziküller, prostat ve vaz deferensde, içeriklerinin prostatik üretraya doğru gidişini sağlayan peristaltik düz kas kasılmaları meydana gelir ve mesane boynu kapanır. Ekspulsiyon fazında ise bulbospongioz ve bulbokavernöz kasın ritmik kasılması ile semen üretra dışına atılır. Normal bir ejakülasyon, tüm bu yapıların koordineli hareketini gerektirmektedir. Emisyon fazında önemli bir rol oynayan vaz deferensin kasılmalarında oluşacak bir anormalliğin, ejakülatuar fonksiyonda da bozukluğa neden olabileceği bildirilmektedir (Tambaro ve ark., 2005).

Erektil disfonksiyon (ED) tedavisinde kullanılan sildenafil, siklik guanozin monofosfat (cGMP)'a özgü fosfodiesteraz (PDE) 5'in seçici inhibitörüdür. Sildenafil PDE5 inhibisyonu ile cGMP derişimini yükselterek korpus kavernosum düz kasında gevşemeye neden olur ve ereksiyonun sürdürülmesini sağlar (Bilge ve ark., 2005). Klinik araştırmalarda sildenafilin, PE'nin tedavisinde SSRI'ların ejakülasyon geciktirici etkisini artırmak amacı ile de kullanılabileceği bildirilmektedir (Rosen ve ark., 1999; Chen, 2007). Fakat bununla çelişen şekilde; sildenafilin SSRI kullanımına bağlı olarak oluşan gecikmiş ejakülasyonun tedavisinde de yararlı olabileceği öne sürülmektedir (Damis ve ark., 1999; Nurnberg, 2001; Seidman, 2006). Ne yazık ki bu konudaki araştırmalar klinik çalışmalarla sınırlıdır. Cinsel yaşam gibi hassas bir konuda klinik çalışmaların en büyük dezavantajı psikolojik faktörlerin ekarte edilememesidir. Bu nedenle bu çalışma, sıçanlarda sertralin, fluoksetin ve sitalopramın sildenafil ile birlikte kullanımının ejakülasyonda önemli rolü olan vaz deferens üzerine etkisini izole sıçan vaz deferensinde araştırmak amacıyla planlanmıştır.

\section{Araştırma Yöntemi}

\section{1. Deney Hayvanları}

Çalışmada, ağırlıkları 200-300 gram arasında değişen, standart yem ve çeşme suyu ile beslenen, sicakl1$\breve{g} 1$ ve bağıl nemi sabit aynı odada 12 saat gece, 12 saat gündüz ortamında tutulan erkek Sprague Dawley sıçanlar kullanıldı. Çalışmalar Helsinki Deklarasyonu'na ve Amerikan Ulusal Sağlik Örgütü (USA NIH) tarafindan bildirilen Laboratuar Hayvanlarının Kullanımına ve Bakımına İlişkin Rehber'e uygun olarak gerçekleştirildi. Ondokuz Mayıs Üniversitesi Tıp Fakültesi Deney Hayvanı Etik Kurulu'nun 04.02.2005 tarih ve DHEK/04 sayılı kararı ile onay alındıktan sonra deneylere başlandı.

\section{2. Lokomotor aktivite ölçümü ve Zorunlu} yüzdürme testi (ZYT)

Lokomotor aktivite ölçümünde zemini $3 \mathrm{~mm}$ çapında, $11 \mathrm{~mm}$ aralıklarla dizilmiş paslanmaz çelik çubuklardan oluşan $39 \times 28 \times 26 \mathrm{~cm}$ boyutlarındaki lokomotor aktivite cihazı (Ugo Basile, 7430-Varese, İtalya) kullanıld. Her bir hayvanın hareketi kafesin zeminindeki çubuklarla bağlantılı bir elektriksel düzenek vasıtasıyla 5 dakika süreyle kaydedildi.

ZYT için, $20 \mathrm{~cm}$ çaplı plexiglasss bir silindir kap, sicaklığı 23-25 0C arasında, $25 \mathrm{~cm}$ suyla dolduruldu. Böylece sıçanların tabana değerek destek almaları önlendi. Hayvanın ortama alışabilmesi için ZYT iki aşamada yapıldı. 14 günlük tedavi öncesinde 15 dakikalık öntest ve 15. gün 5 dakikalık test olmak üzere iki yüzme periyodu uygulandı. Hayvanlar çabalamayı bırakıp, sadece başları suyun üzerinde, ekstremiteleri hareketsiz olarak durduklarında immobil kabul edildi. Dış uyaranlardan etkilenme olasılığını en az düzeye indirmek amacıyla 5 dakikalık test periyodu videoya kaydedildi ve daha sonra sıçanların immobilite süreleri ölçüldü.

\section{3. İn-vitro deneyler}

Siçanlar eter ile uyutularak median kesi ile abdominal kaviteye girildi. Skrotum içeriği dişarıya alınarak vaz deferens çıkarıldı. Çevresindeki yağ ve fasyalardan temizlendi ve orta $1 / 3$ 'lük kısmı alınarak preperatlar hazırland1. İçinde Krebs Henseleit solüsyonu (NaCl: 6,9 g/L, $\mathrm{KCl}: 0,35 \mathrm{~g} / \mathrm{L}, \mathrm{CaCl} 2: 0,28 \mathrm{~g} / \mathrm{L}, \mathrm{MgSO} 4: 0,14 \mathrm{~g} / \mathrm{L}, \mathrm{NaH}-$ CO3: 2,09 g/L, KH2PO4: 0,16 g/L, Glukoz: 1,09 g/L.)bulunan, 370C sabit sıcaklıkta \% 95 O2 + \% 5 CO2 karışımı ile gazlandırılan 20 ml'lik cam organ banyolarma bir ucu izometrik transdusere bağlı olacak şekilde ring elektrodlar yardımıla asıldı. Preparatlara 2 gram istirahat gerilimi 
uyguland1. 60 dakikalık dengelenme periyodundan sonra deney protokolleri uyguland.

Preparatlardan elde edilen yanitlar QuadBridge amplifier (ML118, ADInstruments, UK) aracillğ ile, bilgisayara bağlı PowerLab veri kayıt analiz sistemi (PowerLab/4SP, ADInstruments, UK) tarafindan kaydedildi.

\section{4. Elektriksel alan stimülasyonu (EAS)}

Grass S88 stimulator (Grass, USA)'den sağlanan elektrik akımı sayesinde $3 \mathrm{~mm}$ çaplı ring elektrodlar (MLA0305/8, ADInstruments, UK) yardımıyla preparatlara alan stimulasyonu yapıldı. Stimülasyon parametreleri $100 \mathrm{~V}, 5 \mathrm{~ms}$ süre, $5-80 \mathrm{~Hz}(5,10,20,40,60,80 \mathrm{~Hz})$ olarak belirlendi.

\section{5. İlaçlar}

Sertralin hidroklorür (Fako, Türkiye), Fluoksetin hidroklorür (Abdi İbrahim, Türkiye), Sitalopram hidrobromür (Abdi İbrahim, Türkiye), Sildenafil sitrat (Fako, Türkiye). Kullanılan tüm ilaçlar serum fizyolojik (SF) ile çözüldü ve $1 \mathrm{ml} / \mathrm{kg}$ dozunda intraperitoneal (i.p.) olarak uygulandi.

\section{6. Deney protokolleri}

Her birinde en az 7 adet Sprague Dawley sıçan bulunan deney grupları şu şekilde oluşturuldu. Tüm gruplarda ZYT'nin 15 dakikalık öntestini takiben i.p injeksiyonla ilaçlar uyguland. Kontrol grubundaki siçanlara 14 gün boyunca serum fizyolojik (SF) $(10 \mathrm{ml} / \mathrm{kg})$ ve 15 . gün yine SF $(10 \mathrm{ml} / \mathrm{kg})$ uygulandı. SSRI gruplarına 14 gün boyunca fluoksetin $(20 \mathrm{mg} / \mathrm{kg})$, sertralin $(10 \mathrm{mg} / \mathrm{kg})$ ya da sitalop$\mathrm{ram}(10 \mathrm{mg} / \mathrm{kg})$ verildi ve 15 . gün $\mathrm{SF}(10 \mathrm{ml} / \mathrm{kg})$ uyguland1. SSRI ve sildenafil kombinasyon gruplarında, 14 gün boyunca SSRI, 15 .gün sildenafil $(10 \mathrm{mg} / \mathrm{kg})$ uygulandı. Sildenafil grubuna ise 14 gün boyunca $\mathrm{SF}, 15$. gün sildenafil $(10 \mathrm{mg} / \mathrm{kg})$ uyguland 1.

Son injeksiyondan 20 dakika sonra sıçanlar lokomotor aktivite kafesine konularak spontan motor aktiviteleri ölçüldü. 30. dakikada ZYT'ye tabi tutuldu. Testi takiben vaz deferensleri çıkarılarak organ banyosuna yerleştirildi ve elektriksel alan stimülasyonu (EAS) uygulanarak kasılma yanıtları kaydedildi (Şek. 1).

\section{7. İstatistiksel analiz}

Tüm değerler ortalama \pm standart hata şeklinde verildi. Kasılma yanıtları miligram gerilim olarak ifade edildi. Verilerin normal dağılımının tespitinden sonra çoklu karşılaştırmalar için tek yönlü varyans analizini takiben Bonferoni post-hoc test kullanıldı. Anlamlılık için $\mathrm{p}<0.05$ düzeyi esas alındı.

\section{Sonuçlar}

\section{1. Lokomotor aktivite}

Sertralin, sitalopram ve sildenafil uygulandığın-

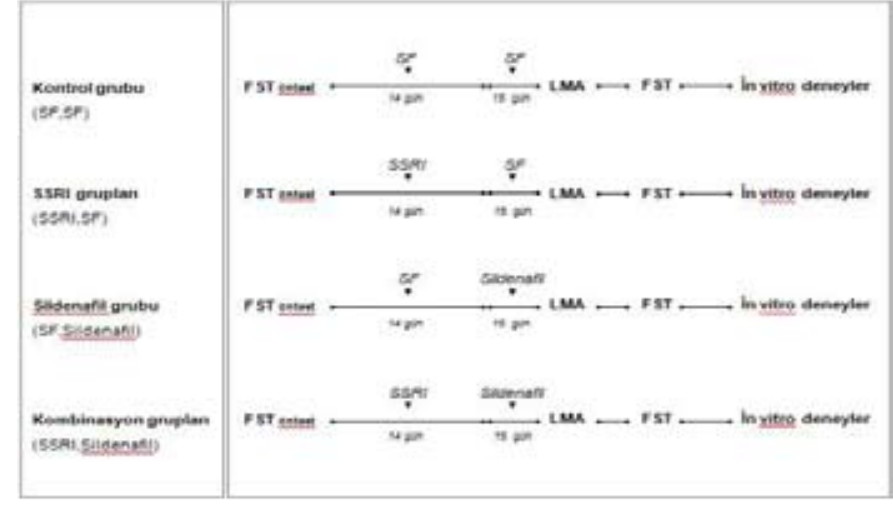

Şek. 1. Deney protokolleri.

da, lokomotor aktivitede kontrol grubuna göre değişiklik görülmezken, fluoksetin grubunda anlamlı olarak azaldı $(\mathrm{p}<0,05)$ (Tablo 1).

Sildenafil, sertralin ya da sitalopramla birlikte uygulandığında, lokomotor aktivitede kontrol grubuna, tek başına SSRI uygulama grubuna ve sildenafil grubuna göre anlamlı değişiklik saptanmadi. Sildenafil fluoksetin ile birlikte uygulandığında ise lokomotor aktivite kontrol grubuna ve sildenafil grubuna göre anlamlı olarak azalırken, fluoksetin grubuna göre anlamlı değişiklik saptanmadi (Tablo1).

\section{2. Zorunlu yüzdürme testinde immobilite sü-} resi ölçümü

Sertralin, fluoksetin ve sitalopram uygulandığında, immobilite süreleri kontrol grubuna göre anlamlı olarak azald $1(p<0,05)$. Sildenafil uygulandığında, immobilite süresinde, kontrol grubuna göre anlamlı değişiklik saptanmadi (Tablo 1).

Sildenafil sertralin ya da sitalopramla birlikte uygulandığında, immobilite süresinde kontrol grubuna, sildenafil grubuna ve tek başina SSRI uygulama grubuna göre anlamlı değiş̧iklik saptanmadı. Sildenafil, fluoksetin ile birlikte uygulandığında ise immobilite süresi kontrol grubuna ve sildenafil grubuna göre anlamlı olarak azalırken, tek başına fluoksetin uygulama grubuna göre anlamlı değişiklik saptanmadı (Tablo 1).

\section{3. Elektriksel alan stimulasyonu (EAS) nun vaz deferensteki etkisi}

$100 \mathrm{~V}, 5 \mathrm{~ms}$ süre, $\operatorname{artan}$ frekansta $(5,10,20,40,60$, $80 \mathrm{~Hz}$ ) EAS uygulanarak kasılma yanıtları alındı (Şek. 2). Sertralin, fluoksetin ve sitalopram uygulanan sıçanlarda vaz deferens kasılmaları kontrol grubuna göre tüm frekanslarda anlamlı olarak baskıland $1(\mathrm{p}<0,05)$ (Şek. 2, 3). Sildenafil uygulanan sıçanlarda, vaz deferens kasılmaları kontrol grubuna göre değişiklik oluuşturmadı (Şek. $4,5,6)$.

Sildenafil sertralinle birlikte uygulandığında, vaz deferens kasılmaları kontrol ve sildenafil grubuna göre tüm frekanslarda anlamlı olarak baskılandı $(\mathrm{p}<0.05)$ (Şek. 
Tablo 1. SSRI ve sildenafil kombinasyonlarının uygulamasının lokomotor aktivite ve FST'de immobilite süresi üzerine etkileri.

\begin{tabular}{|c|c|c|c|}
\hline Mas urovionsmat & Doe $(1,20)$ & 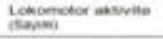 & ingil \\
\hline 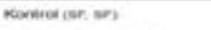 & 10mexa. $70 m=\times g$ & $100.00 n 1470$ & Tea. 1teats \\
\hline fintraten isetim an? & tomoteg, toming & 114.570102 & +50, $.0013,59^{\circ}$ \\
\hline 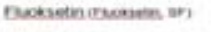 & 20 nove, 10mave & $00,50=1,4^{*}$ & $900,50 x 12,40^{*}$ \\
\hline 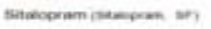 & tomoto. 10matro & 102,abus,az & 14e7tata, os \\
\hline 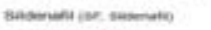 & $100 \times x+0,100+0 \times 0$ & 146. $16=200$. 50 & 17etestra.24 \\
\hline 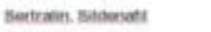 & tomoka tomaxy & 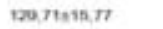 & sou zante. 06 \\
\hline 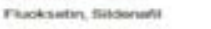 & pomsoka ramovo & Br, $\max 10,02 \times$ & саз, \\
\hline 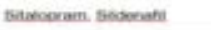 & tomova tomovo & tea. 14.0 .96 & secoorat 10 \\
\hline
\end{tabular}

4). Sertralin grubuna göre ise istatistiksel olarak anlamlı değişiklik oluşturmadı.

Sildenafil fluoksetinle birlikte uygulandığında, vaz deferens kasılmaları kontrol grubuna göre tüm frekanslarda baskiland1. Meydana gelen kasılmadaki azalmalar 20, 40, 60 ve $80 \mathrm{~Hz}$ frekanslarında anlamlı bulundu $(\mathrm{p}<0,05)$. Fluoksetin grubuna göre, tüm frekanslarda kasılmalarda istatistiksel olarak anlamlı artış gözlendi $(p<0,05)$. Sildenafil grubuna göre ise kasılmalar tüm frekanslarda bask1land. Meydana gelen kasılmadaki azalmalar 60 ve $80 \mathrm{~Hz}$ frekanslarında anlamlı bulundu $(\mathrm{p}<0,05)$ (Şek. 5).

Sildenafil sitalopramla birlikte uygulandığında, vaz deferens kasılmaları kontrol grubuna göre tüm frekanslarda istatistiksel olarak anlamlı azalma gösterdi $(p<0,05)$. Sitalopram grubuna göre, tüm frekanslarda istatistiksel olarak anlamlı artış gösterdi $(\mathrm{p}<0,05)$. Sildenafil grubuna göre ise istatistiksel olarak anlamlı değişiklik göstermedi (Şek. 6).

\section{Tartışma}

Çalıșmamızda, sıçanlarda sertralin, fluoksetin ve sitalopramın sildenafil ile birlikte kullanımının, ejakülasyonda önemli rolü olan vaz deferens üzerine etkisi, izole sıçan vaz deferensinde araştırıldı. Sertralin, fluoksetin ve sitalopramın kronik uygulamasının, EAS'ye bağlı oluşan
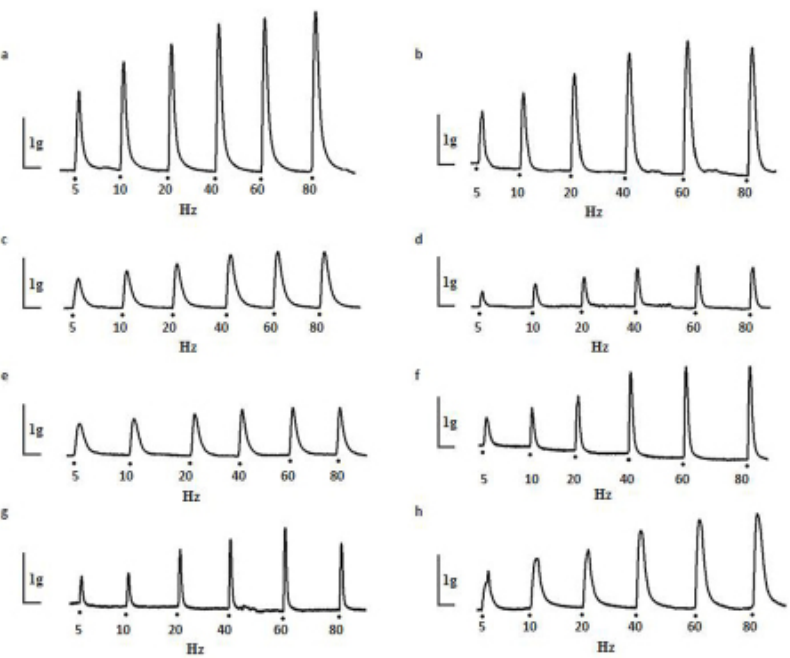

Şek. 2. İzole sıçan vaz deferensinde $100 \mathrm{~V}, 5 \mathrm{~ms}$ süre, artan frekansta $(5,10,20$ 40,60, $80 \mathrm{~Hz}$ ) elektriksel alan stimulasyonuna yanıt trasesi: (a) $10 \mathrm{ml} / \mathrm{kg} \mathrm{SF}$, $10 \mathrm{ml} / \mathrm{kg} \mathrm{SF}$ uygulamasi; (b) $10 \mathrm{ml} / \mathrm{kg} \mathrm{SF}, 10 \mathrm{mg} / \mathrm{kg}$ sildenafil uygulaması; (c) $10 \mathrm{mg} / \mathrm{kg}$ sertralin, $10 \mathrm{ml} / \mathrm{kg} \mathrm{SF}$ uygulamas1; (d) $10 \mathrm{mg} / \mathrm{kg}$ sertralin, $10 \mathrm{mg} / \mathrm{kg}$ sildenafil uygulaması (e) $20 \mathrm{mg} / \mathrm{kg}$ fluoksetin, $10 \mathrm{ml} / \mathrm{kg}$ SF uygulamas1; (f) $20 \mathrm{mg} / \mathrm{kg}$ fluoksetin, $10 \mathrm{mg} / \mathrm{kg}$ sildenafil uygulamasi; $(\mathrm{g}) 10 \mathrm{mg} / \mathrm{kg}$ sitalopram, $10 \mathrm{ml} / \mathrm{kg}$ SF uygulamasi; (h) $10 \mathrm{mg} / \mathrm{kg}$ sitalopram, $10 \mathrm{mg} / \mathrm{kg}$ sildenafil uygulamas1.

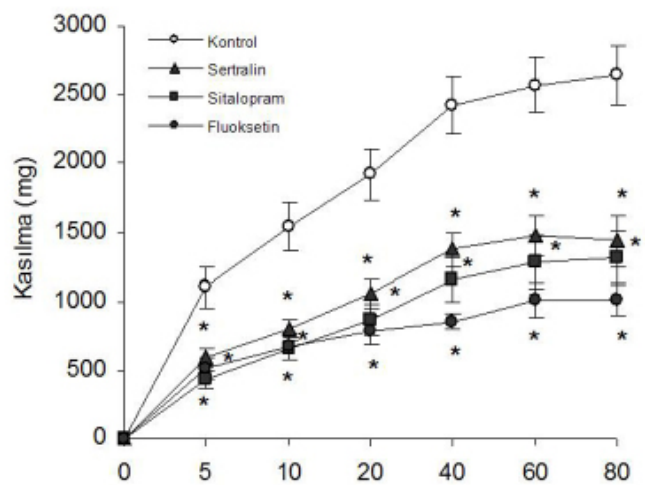

Sekil 3. Sertralin $10 \mathrm{mg} / \mathrm{kg}$, fluoksetin $20 \mathrm{mg} / \mathrm{kg}$ ya da sitalopram $20 \mathrm{mg} / \mathrm{kg}$ uygulanan sıçanların vaz deferens preperatlarının, EAS'ye bağlı kasılma yanıtlar1. Veriler ortalama \pm standart hata olarak verilmistir $(\mathrm{n}=7){ }^{*} \mathrm{p}<0.05$ kontrol grubu ile karsılastırıldığında.

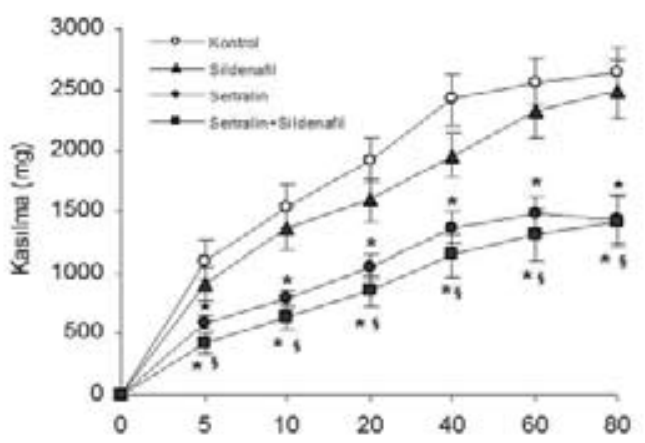

Şek. 4. Sildenafil $10 \mathrm{mg} / \mathrm{kg}$ ve sertralin $10 \mathrm{mg} / \mathrm{kg}$ kombinasyonu uygulanan sıçanların vaz deferens preperatlarının, EAS'ye bağlı kasılma yanıtları. Veriler ortalama \pm standart hata olarak verilmistir $(n=7) . * p<0.05$ kontrol grubu ile karsılastırıldığında, \#p <0.05 sildenafil grubu ile karsılastırıldığında.

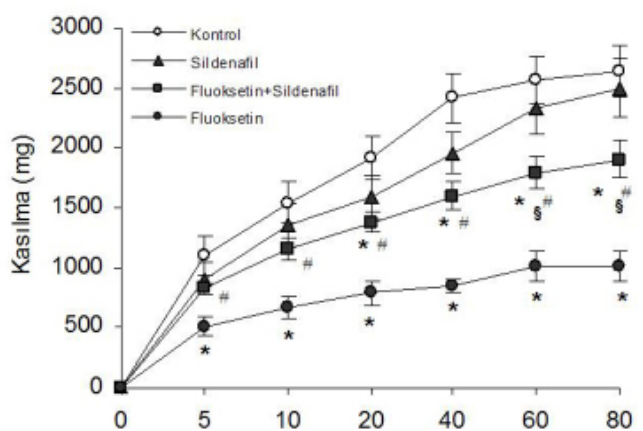

Şek. 5. Sildenafil $10 \mathrm{mg} / \mathrm{kg}$ ve fluoksetin $20 \mathrm{mg} / \mathrm{kg}$ kombinasyonu uygulanan s1çanların vaz deferens preperatlarının, EAS'ye bağlı kasılma yanıtları. Veriler ortalama \pm standart hata olarak verilmistir $(n=7)$. $* p<0,05$ kontrol grubu ile karsılastırıldığında, $\S \mathrm{p}<0,05$ fluoksetin grubu ile karsılastırıldığında, \#p $<0,05$ sildenafil grubu ile karsılastırıldığında.

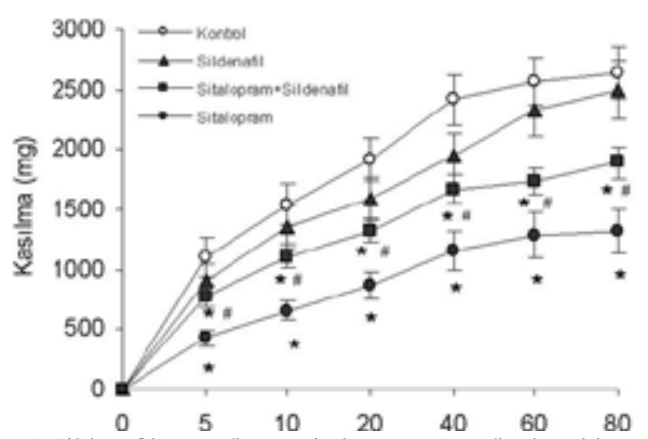

ek. 6. Sildenafil $10 \mathrm{mg} / \mathrm{kg}$ ve sitalopram $10 \mathrm{mg} / \mathrm{kg}$ kombinasyonu uygulanan s1çanların vaz deferens preperatlarının, EAS'ye bağlı kasılma yanıtları. Veriler ortalama \pm standart hata olarak verilmistir $(n=7)$ * $p<0,05$ kontrol grubu ile karsılastırıldığında, $\S p<0,05$ sitalopram grubu ile karsılastırıldığında. 
vaz deferensin kasılmalarını azalttığ1 görüldü. Sildenafil tek başına uygulandığında vaz deferensin EAS'ye bağlı kasılmalarında anlamlı değişiklik oluşturmazken; fluoksetin ve sitaloprama bağl1 olarak azalan vaz deferens kasılma yanıtlarını anlamlı düzeyde artırdı. Sertraline bağlı olarak azalan vaz deferens kasılma yanıtlarını kontrol grubuna ve sildenafil grubuna göre daha da azaltırken, sertralin grubuna göre ise değiştirmedi.

Antidepresan ilaçların, FST'de immobiliteyi azaltmaları, LMA' da ise artış oluşturmamaları beklenir (Porsolt ve ark., 1977; Cryan ve ark., 2005). Bu çalışmada kullandığımız SSRI dozlarının antidepresan benzeri aktivitesini kanıtlamak için FST'deki immobilite sürelerine bakıld1. Her üç grupta da antidepresan-benzeri etkiyle tutarlı şekilde immobilite süreleri azaldı. Bu immobilitedeki azalmanın nonspesifik bir lokomotor aktivite artışına bağlı olmadığını kanıtlamak için de LMA'larına bakıldı ve hiçbir grupta artış gözlenmedi. Fluoksetin uygulanan grupta LMA'da azalma görülmesine rağmen, bu FST'de immobilite azalmasını engellemedi.

SSRI'ların ve sildenafilin hem santral, hem de periferik etkileri konusunda birçok muhtemel mekanizma öne sürülse de, henüz ejakülasyondaki etki mekanizmaları tam olarak anlaşılamamıştır. SSRI'lara bağlı ejakülasyon inhibisyonunun periferik mekanizmalarını araştıran Kalyoncu ve ark., 10-4 M sertralinin, izole sıçan vaz deferensinin noradrenalin (NA), potasyum klorür $(\mathrm{KCl}), 5-\mathrm{HT}$ ve EAS'ye bağlı kasılmalarını inhibe ettiğini ve ejakülasyondaki gecikmenin buna bağlı olabileceğini belirtmişlerdir (Kalyoncu ve ark., 1999). Özyavuz ve ark.'da sıçanlara kronik olarak uygulanan sertralinin de izole siçan vaz deferensinin kasılmalarını inhibe ettiğini göstermişler; sertralinin periferik etkilerinde, santral etkilerinden sorumlu tutulan serotonin geri alımının inhibisyonundan başka, kalsiyum girişinin ya da noradrenalin geri alım inhibisyonunun da etkili olabileceğini bildirmişlerdir (Özyavuz ve ark., 2004). Medina ve ark., elektif vazektomi vakalarından temin edilen insan vaz deferens preperatlarında, sertralin ve fluoksetinin 10-5 M dozda, NA'ya ve KCl'ye bağl kasılmaları zayıflattığını ve $\mathrm{KCl}$ polarize preperatlarda ise kalsiyum klorürün indüklediği kasılmaları azalttığını; bu etkinin adrenerjik reseptörlerden bağımsız, kalsiyum girişi inhibisyonu sonucu oluştuğunu öne sürmüşlerdir (Medina ve ark., 2000).

Sildenafil, etkilerini nitrik oksit/siklik GMP (NO/ cGMP) yolağı üzerinden göstermektedir. PDE5 inhibisyonu ile cGMP'yi artırarak korpus kavernozum düz kasında gevşemeye neden olan sildenafilin, noradrenerjik transmisyonu inhibe ettiği, ama bu inhibisyonu cGMP birikiminden bağımsız şekilde, potasyum kanallarını inhibe ederek oluşturduğu öne sürülmüştür (Medina ve ark., 2000). Bilge ve ark. ise sildenafilin, siçan vaz deferens preperatlarında EAS ile oluşturulan kasılmaları inhibe ettiğini ve bu inhibisyonda ATP'ye bağlı mekanizmaların rolü olduğunu bildirmişlerdir (Bilge ve ark., 2005)

SSRI'lar serotonerjik taşıyıcıları (5-HTT) inhibe ederek sinaptik aralıkta serotonin seviyesini artırırlar. Seksüel fonksiyon bozukluğu oluşturmalarında, serotonin seviyesindeki bu artışın önemli rolü olduğu düşünülmektedir (Rosen ve ark., 1999; Sukoff Rizzo ve ark., 2009). Ejakülasyonun düzenlenmesinde, serotonin (5-HT) inhibitör özelliği ile en önemli nörotransmiterdir (Hull ve ark., 2004). Beyin ve spinal kord'un çeşitli bölgelerinde ejakülasyonu düzenleyen çok sayıda serotonin reseptörü bulunmaktadır. 5-HT1A reseptör aktivasyonunun ejakülasyonu hızlandırdığ 1 ; 5-HT1B ve 5-HT2C reseptörlerinin aktivasyonunun ise ejakülasyonda inhibe edici rol oynadıkları bildirilmektedir (Giuliano ve Clement, 2005).

SSRI'lara bağli gecikmiş ejakülasyonda, 5-HT reseptörlerinin ejakülasyon süresinin regülasyonunda önemli rol oynadığ 1 vurgulansa da, son yayınlarda santral serotonin nörotransmisyonunu sağlayan 5-HTT'nin de bu regülasyonda önemli etkileri olabileceğine işaret edilmektedir (Abdel-Hamid ve ark., 2009). 5-HTT, sinaptik aralıkta serotoninin kalış süresini, kullanılabilirliğini ve ileti kapasitesini kontrol eden, hücre membranında yerleşik spesifik bir taşıyıcıdır. Aynı zamanda ejakülasyonda gecikmeye neden oldukları bilinen SSRI'ların da ana hedefidir (Giuliano ve Clement, 2006). Uzun dönem PE problemi olan erkeklerdeki genetik yatkınlığı araştıran iki ayrı çalışmada, 5-HTT'nin genetik polimorfizminin ejakülasyon latensini önemli oranda etkilediği görülmüştür (Janssen ve ark., 2009; Ozbek ve ark., 2009). Farmakogenetik çalışmalarda da, 5-HTT'nin genetik varyasyonlarının, SSRI'ların klinikte oluşturdukları yanıtları ve yan etkileri etkilediği ortaya konulmuştur (Perlis ve ark., 2003; Arias ve ark., 2005). SSRI tedavisi alan hastalarda 5-HTT'nin yaygın bir genetik varyasyonunun, seksüel disfonksiyon ile birlikteliği de rapor edilmiştir (Bishop ve ark., 2009)

SSRI'ların 5-HTT'yi inhibe ederek sinaptik serotonin düzeyini artırdığı bilinmektedir. Sildenafilin ise cGMP seviyesini artırarak 5-HTT'nin aktivasyonunu konsantrasyona ve zamana bağımlı olarak artırdığı gösterilmiştir (Zhu ve ark., 2004). Bu durum sildenafilin ve SSRI'ların serotonin nörotransmisyonunda 5-HTT üzerinde birbirine zit etkileri olduğunu göstermektedir. Bütün SSRI'ların 5-HTT'ye bağlanma güçleri birbirinden farklıdır. 5-HTT afinitelerine göre IC50 değerleri sıçanlarda; sertralin, fluoksetin ve sitalopram için sırasılya $0,3,2$ ve 0,8'dir (Lenox ve Frazer, 2002). 
Güçlüden zayıfa doğru sıralarsak "sertralin>sitalopram> fluoksetin" olduğu görülmektedir.

Çalışmamızda sildenafilin, fluoksetin ve sitaloprama bağlı olarak baskılanan vaz deferens kasılma yanıtlarında baskılanmayı azalttığı görülmüştü. Ejakülasyon regülasyonunda ve SSRI'lara bağlı oluşan seksüel yan etkilerde 5-HTT'nin rolü olabileceğini gösteren çalışmalar ile, SSRI'larla sildenafilin 5-HTT üzerindeki zit etkilerini bildiren çalışmalar göz önüne alınırsa; sildenafilin, 5-HTT'ye bağlanma güçleri daha düşük olan fluoksetin ve sitalopramın vaz deferensin kasılma yanıtlarındaki etkisini engelleyerek baskılanmayı azalttığı, fakat daha kuvvetli bağlanan sertralinin etkisini engelleyemediği düşünülebilir. Sildenafilin farklı SSRI'larla farklı sonuçlar oluşturmasının nedeni, SSRI'ların 5-HTT'ye bağlanma güçlerinin farklılı̆̆ olabilir.
$\mathrm{Bu}$ sonuçlara göre, sildenafilin, fluoksetin ve sitaloprama bağlı oluşan ejakülasyon gecikmesinde, vaz deferens motilitesini artırarak normal ritmik vaz deferens kasılmalarının oluşmasını sağladığı ve sonuç olarak ejakülasyondaki gecikmeyi azaltmakta etkili olabileceği düşünüldü. Fakat aynı zamanda sertralinle birlikte kullanıldığında vaz deferens motilitesini artıramadığı da saptandi. Daha önce farklı SSRI'larla yapılmış klinik çalışmalardaki çelişkili sonuçlarda bildirildiği gibi, bizim bulgularımız da sildenafilin bazı SSRI ilaçlara bağlı gelişen ejakülasyon gecikmesinde yararlı olabileceğini, bazılarında ise olamayacağını düşündürmektedir. SSRI ve sildenafil kombinasyonlarının ejakülasyon üzerine etkilerinin mekanizmasının net olarak ortaya konabilmesi için daha ileri çalışmalara ihtiyaç vardır.

\section{Kaynaklar}

Abdel-Hamid, I.A., Jannini, E.A., Andersson, K.E., 2009. Premature ejaculation: focus on therapeutic targets.Expert. Opin. Ther. Targets. 13,175-193.

Arias, B., Catalán, R., Gastó, C., Gutiérrez, B., Fañanás, L., 2005. Evidence for a combined genetic effect of the 5-HT(1A) receptor and serotonin transporter genes in the clinical outcome of major depressive patients treated with citalopram. J. Psychopharmacol. 19,166-172.

Bilge, S.S., Kesim, Y., Kurt, M., Aksoz, E., Celik, S., 2005. Possible role of sildenafil in inhibiting rat vas deferens contractions by influencing the purinergic system. Int. J. Urol. 12,829-834.

Bishop, J.R., Ellingrod, V.L., Akroush, M., Moline, J., 2009. The association of serotonin transporter genotypes and selective serotonin reuptake inhibitor (SSRI)-associated sexual side effects: possible relationship to oral contraceptives. Hum. Psychopharmacol. 24,207-215.

Chen, J., Keren-Paz, G., Bar-Yosef, Y., Matzkin, H., 2007. The role of phosphodiesterase type 5 inhibitors in the management of premature ejaculation: a critical analysis of basic science and clinical data. Eur. Urol. 52,1331-1339.

Cryan, J.F., Valentino, R.J., Lucki, I., 2005. Assessing substrates underlying the behavioral effects of antidepressants using the modified rat forced swimming test. Neurosci. Biobehav. Rev. 29,547-569.

Damis, M., Patel, Y., Simpson, G.M., 1999. Sildenafil in the Treatment of SSRI-Induced Sexual Dysfunction: A Pilot Study. Prim. Care Companion. J. Clin. Psychiatry. 1, 184-187.

Giuliano, F., Clement, P., 2005. Neuroanatomy and physiology of ejaculation. Annu. Rev. Sex. Res; 16, 190-216.

Giuliano, F., Clement, P., 2006. Serotonin and premature ejaculation: from physiology to patient management. Eur. Urol. 50, 454466.

Hull, E.M., Muschamp, J.W., Sato, S., 2004. Dopamine and serotonin: influences on male sexual behavior. Physiol. Behav. 83, 291307.

Janssen, P.K., Bakker, S.C., Réthelyi, J., Zwinderman, A.H., Touw, D.J., Olivier, B., Waldinger, M.D., 2009. Serotonin transporter promoter region (5-HTTLPR) polymorphism is associated with the intravaginal ejaculation latency time in Dutch men with lifelong premature ejaculation. J. Sex. Med. 6, 276-284.

Kalyoncu, N.I., Ozyavuz, R., Karaoglu, S., 1999. Sertraline inhibits the contractile responses to noradrenaline, KCl and electrical field stimulation of rat isolated vas deferens. J. Auton Pharmacol. 19, 365-369.

Lenox, R.A., Frazer, A., 2002. Mechanism of action of antidepressants and mood stabilizers. In: Davis KL et al, editors. Neuropsychopharmacology: The Fifth Generation of Progress. Nashville, TN: 1139-1163.

Medina, P., Segarra, G., Ballester, R., Chuan, P., Domenech, C., Vila, J.M., Lluch, S., 2000. Effects of antidepressants in adrenergic neurotransmission of human vas deferens. Urology. 55,592-597.

Medina, P., Segarra, G., Torondel, B., Chuan, P., Domenech, C., Vila, J.M., Lluch, S., 2000. Inhibition of neuroeffector transmission in human vas deferens by sildenafil. Br. J. Pharmacol. 131, 871-874.

Nurnberg, H.G., 2001. Managing treatment-emergent sexual dysfunction associated with serotonergic antidepressants: before and after sildenafil. J. Psychiatr. Pract. 7, 92-108.

Nurnberg, H.G., 2008. An evidence-based review updating the various treatment and management approaches to serotonin reuptake inhibitor-associated sexual dysfunction. Drugs Today (Barc). 44, 147-168. 
Ozbek, E., Tasci, A.I., Tugcu, V., Ilbey, Y.O., Simsek, A., Ozcan, L., Polat, E.C., Koksal, V., 2009. Possible association of the 5-HTTLPR serotonin transporter promoter gene polymorphism with premature ejaculation in a Turkish population. Asian. J. Androl. 11, 351-355.

Ozyavuz, R., Kalyoncu, N.I., Karaoglu, S., 2004. Long-term use of sertraline leads to alterations in contractility of rat isolated vas deferens. Urol. Res. 32, 20-24.

Perlis, R.H., Mischoulon, D., Smoller, J.W., Wan, Y.J., Lamon-Fava, S., Lin, K.M., Rosenbaum, J.F., Fava, M., 2003. Serotonin transporter polymorphisms and adverse effects with fluoxetine treatment. Biol. Psychiatry. 54,879-883.

Porsolt, R.D., Le Pichon, M., Jalfre, M., 1977. Depression: a new animal model sensitive to antidepressant treatments. Nature. 266,730-732.

Rosen, R.C., Lane, R.M., Menza, M., 1999. Effects of SSRIs on sexual function: a critical review. J. Clin. Psychopharmacol. 19, 67-85

Salonia, A., Maga, T., Colombo, R., Scattoni, V., Briganti, A., Cestari, A., Guazzoni, G., Rigatti, P., Montorsi, F., 2002. A prospective study comparing paroxetine alone versus paroxetine plus sildenafil in patients with premature ejaculation. J. Urol. 168, 24862489.

Seidman, S., 2006. Ejaculatory dysfunction and depression: pharmacological and psychobiological interactions. Int. J. Impot. Res. $18,33-38$.

Sukoff Rizzo, S.J., Pulicicchio, C., Malberg, J.E., Andree, T.H., Stack, G.P., Hughes, Z.A., Schechter, L.E., Rosenzweig-Lipson, S., 2009. 5-HT(1A) receptor antagonism reverses and prevents fluoxetine-induced sexual dysfunction in rats. Int. J. Neuropsychopharmacol. 12, 1045-1053.

Tambaro, S., Ruiu, S., Dessi, C., Mongeau, R., Marchese, G., Pani, L., 2005. Evaluation of tamsulosin and alfuzosin activity in the rat vas deferens: relevance to ejaculation delays. J. Pharmacol. Exp. Ther. 312, 710-717.

Waldinger, M.D., Olivier, B., 2004. Utility of selective serotonin reuptake inhibitors in premature ejaculation. Curr. Opin. Investig. Drugs. 5, 743-747.

Zhu, C.B., Hewlett, W.A., Francis, S.H., Corbin, J.D., Blakely, R.D., 2004. Stimulation of serotonin transport by the cyclic GMP phosphodiesterase-5 inhibitor sildenafil. Eur. J. Pharmacol. 504, 1-6. 